\title{
The Homogeneous Forcing of Mercury Oxidation to Provide Low-Cost Capture
}

\author{
Annual Report \\ Start Date: July 1, 2003 \\ End Date: June 30, 2004 \\ Authors: John C. Kramlich and Linda Castiglone \\ Issued April 2006 \\ DOE Grant No. DE-FG26-03NT41808 \\ Department of Mechanical Engineering \\ University of Washington \\ Box 352600 \\ Seattle, Washington 98195-2600
}




\section{Disclaimer}

This report was prepared as an account of work sponsored by an agency of the United States Government. Neither the United States Government nor any agency thereof, nor any of their employees, makes any warranty, express or implied, or assumes any legal liability or responsibility for the accuracy, completeness, or usefulness of any information, apparatus, product, or process disclosed, or represents that its use would not infringe privately owned rights. Reference herein to any specific commercial product, process, or service by trade name, trademark, manufacturer, or otherwise does not necessarily constitute or imply its endorsement, recommendation, or favoring by the United States Government or any agency thereof. The views and opinions of the authors expressed herein do not necessarily state or reflect those of the United States Government or any agency thereof. 


\begin{abstract}
Oxidized mercury formed in combustors $\left(e . g ., \mathrm{HgCl}_{2}\right)$ is much more easily captured in existing pollution control equipment (e.g., wet scrubbers for $\mathrm{SO}_{2}$ ) than elemental mercury. This is principally due to the high solubility of the oxidized form in water. Work over the last several years in our laboratory and elsewhere has identified the general outlines of the homogeneous chemistry of oxidation. The goal of the work reported here is to make use of this knowledge of the oxidation mechanism to devise simple and inexpensive ways to promote the oxidation. The hypothesis is that simple fuels such as hydrogen or $\mathrm{CO}$ can promote oxidation via the free radicals they generate during their decomposition. These free radicals then promote the formation of $\mathrm{Cl}$ from $\mathrm{HCl}$ via reactions such as $\mathrm{OH}+\mathrm{HCl} \rightarrow \mathrm{H}_{2} \mathrm{O}+\mathrm{Cl}$. The $\mathrm{Cl}$ (and $\mathrm{Cl}_{2}$ derived from $\mathrm{Cl}$ recombination) are considered the principal oxidizing species. In our studies, mercury vapor is exposed to $\mathrm{HCl}$ under isothermal conditions in a gas containing $\mathrm{N}_{2}, \mathrm{O}_{2}$, and $\mathrm{H}_{2} \mathrm{O}$. The experiments systematically explore the influence of reaction temperature, $\mathrm{HCl}$ concentration, and $\mathrm{H}_{2} \mathrm{O}$ concentration. These baseline conditions are then perturbed by the addition of varying amounts of $\mathrm{H}_{2}, \mathrm{CO}$, and $\mathrm{H}_{2} / \mathrm{CO}$ added jointly. The following report describes the experimental facilities and the results of the baseline tests completed in the first year. These results show that temperature and $\mathrm{HCl}$ promote oxidation, which is consistent with our earlier work and work reported elsewhere. In addition, we systematically explored the influence of $\mathrm{H}_{2} \mathrm{O}$ concentration on oxidation. The inhibition of oxidation by $\mathrm{H}_{2} \mathrm{O}$ had been previously predicted from chemical kinetic modeling, but the present data represent the first experimental evidence of the role of $\mathrm{H}_{2} \mathrm{O}$ in reducing oxidation.
\end{abstract}




\section{Table of Contents}

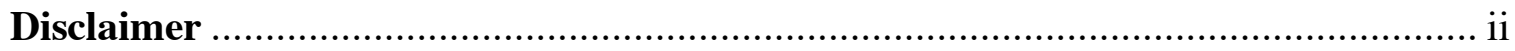

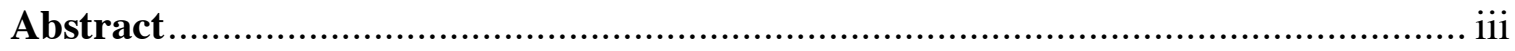

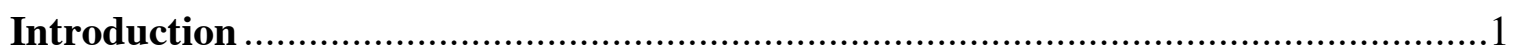

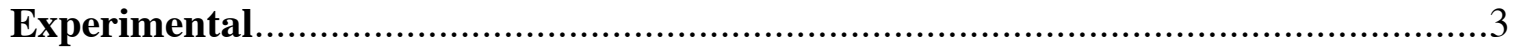

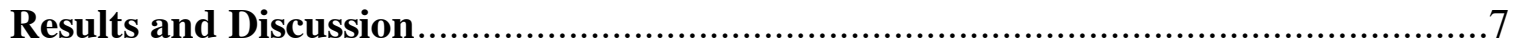

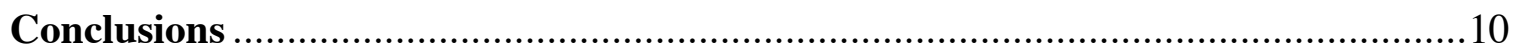

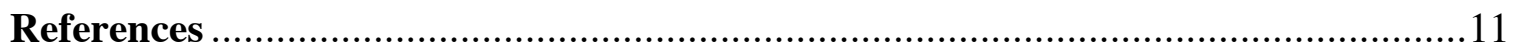

\section{List of Figures}

Figure 1. Quartz flow reactor system and clamshell oven .......................................

Figure 2. Manifold flow panel.......................................................................

Figure 3. Schematic cross-section of the quartz flow reactor ..................................

Figure 4. Comparison of oxidation extents for various experiments ...........................

Figure 5. Influence of water vapor concentration on $\mathrm{Hg}$ oxidation................................

Figure 6. Oxidation of mercury by $\mathrm{HCl}$ in the absence of promoters

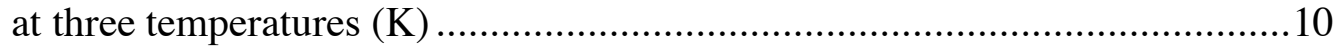




\section{Introduction}

The EPA has recently released proposed mercury regulations for the nation's coal-fired electric generation plants. These regulations focus initially on moderate levels of emission reduction and they include an emissions trading option. The regulations thus provide a potential niche for technologies that deliver a moderate amount of control at a very low cost as opposed to high efficiency, but very high cost technologies (e.g., activated carbon spray drying). Our research focuses on the fact that mercury emissions are partitioned into (1) elemental mercury, and (2) bivalent mercury (usually assumed to be $\mathrm{HgCl}_{2}$ ). Bivalent mercury is water-soluble and is removed to a reasonable level of efficiency by aqueous back-end pollution control systems. Thus, the limestone slurry $\mathrm{SO}_{2}$ scrubbers present in many plants can also remove much of the oxidized portion of the mercury emission at no additional cost.

This approach works best if the mercury can be forced to the oxidized state. Until a few years ago the mechanism governing the oxidation of mercury in coal combustion systems was unknown, so devising a way to promote the oxidation was not possible. Work in our laboratory and elsewhere has uncovered the broad outline of how mercury is homogeneously oxidized, and makes it possible to propose measures to promote oxidation. Here we will briefly review the oxidation mechanism (Sliger et al, 2000), and then discuss the proposed approach for promoting oxidation.

The community generally accepts that during combustion the mercury contained in coal is quantitatively released to the gas phase as elemental mercury, the favored equilibrium product at flame temperatures. At the same time, the coal chlorine is converted mostly to $\mathrm{HCl}$. The direct reaction of $\mathrm{Hg}+\mathrm{HCl}$ is hindered by too large of an energy barrier to be of consequence under normal combustion conditions. A fraction of the $\mathrm{HCl}$ does, however, disassociate to produce atomic chlorine $(\mathrm{Cl})$, which is capable of reacting with $\mathrm{Hg}$. The reaction:

$$
\mathrm{Hg}+\mathrm{Cl}+\mathrm{M} \rightarrow \mathrm{HgCl}+\mathrm{M}
$$

is believed to proceed near the collisional limit. At high temperatures, however, reverse reactions destroying the $\mathrm{HgCl}$ are fast and no appreciable $\mathrm{HgCl}$ concentration appears.

As the gases cool, the $\mathrm{Cl}$ begins to recombine via:

$$
\mathrm{Cl}+\mathrm{Cl}+\mathrm{M} \rightarrow \mathrm{Cl}_{2}+\mathrm{M}
$$

This reaction is relatively slow, and appears to allow a significant amount of $\mathrm{Cl}$ to persist into relatively low temperature environments. Under these conditions the oxidation reaction noted above will proceed. In addition, reactions involving the $\mathrm{Cl}_{2}$ generated by the recombination reaction will also proceed.

$$
\begin{gathered}
\mathrm{Hg}+\mathrm{Cl}_{2} \rightarrow \mathrm{HgCl}+\mathrm{Cl} \\
\mathrm{HgCl}+\mathrm{Cl}+\mathrm{M} \rightarrow \mathrm{HgCl}_{2}+\mathrm{M}
\end{gathered}
$$




$$
\mathrm{HgCl}+\mathrm{Cl}_{2} \rightarrow \mathrm{HgCl}_{2}+\mathrm{Cl}
$$

Thus, the general idea is that:

- The high temperature environment provides the reactive chlorine species needed for oxidation, but no net oxidation occurs here due to fast reverse reactions that convert $\mathrm{HgCl}$ and $\mathrm{HgCl}_{2}$ back to $\mathrm{Hg}$.

- The reactive chlorine species survive the thermal quench of the flame gases (which occurs either in a probe or due to heat extraction in the furnace).

- At lower temperatures the reactive chlorine species oxidize the $\mathrm{Hg}$, and the reverse decomposition reactions are negligible.

These mechanistic ideas have undergone continued refinement over the last five years. First, the role of $\mathrm{NO}$ as a mercury oxidation deactivator has been attributed to the loss of $\mathrm{OH}$ (which is important for converting $\mathrm{HCl}$ to $\mathrm{Cl}$ ) via (Niksa et al., 2001, Livengood et al., 2002):

$$
\mathrm{NO}+\mathrm{OH}+\mathrm{M} \rightarrow \mathrm{HONO}+\mathrm{M}
$$

Additional reactions have been proposed by which sulfur species can generate chlorine atoms (Qiu et al., 2003). Also, although direct formation of $\mathrm{HgO}$ in the absence of chlorine is not indicated, reactions that generate $\mathrm{HgO}$ through chlorine intermediates have been suggested $(\mathrm{Xu}$ et al., 2003). For example:

$$
\mathrm{Hg}+\mathrm{ClO} \rightarrow \mathrm{HgO}+\mathrm{Cl}
$$

Given this overall scenario, how would one enhance the conversion of elemental $\mathrm{Hg}$ to the water-soluble oxidized form needed to take advantage of capture by existing wet pollution control equipment? Since the conversion of $\mathrm{HCl}$ to $\mathrm{Cl}$ is primarly via:

$$
\mathrm{HCl}+\mathrm{OH} \rightarrow \mathrm{Cl}+\mathrm{H}_{2} \mathrm{O}
$$

one approach is to enhance free radical concentrations in the post-flame region. Our approach is to introduce small amounts of species such as $\mathrm{H}_{2}$ or $\mathrm{CO}$ at appropriate locations in the post flame gases. The oxidation of these species generate superequilibrium free radical concentrations that can promote $\mathrm{Cl}$ formation in the down stream region, where it can be effectively used in increasing $\mathrm{Hg}$ oxidation. In a practical system, the source of the $\mathrm{H}_{2}$ or $\mathrm{CO}$ would be from a small on-line natural gas reformer.

The goals of the research presented here are to answer the following questions:

- Will this approach work?

- Assuming it will, how much agent should be injected, and what is the optimum injection temperature?

- Is $\mathrm{H}_{2}$ versus $\mathrm{CO}$ the preferred agent, or does a mixture of the two provide the best results.

- Can the results be accurately described by chemical kinetic models? 
- If so, can these models be used to accurately extrapolate the results to practical, nonisothermal systems (i.e., where should the agent be injected, and how much should be injected to achieve best results under typical boiler time/temperature histories).

\section{Experimental}

The experiments are performed in a quartz flow reactor system. This provides an approximately 0.5 second isothermal reaction environment where the temperature can be varied from ambient to $1700 \mathrm{~K}$. Figure 1 shows the clamshell oven that contains the quartz flow reactor. The various reagent gases $\left(\mathrm{N}_{2}, \mathrm{O}_{2}, \mathrm{HCl}, \mathrm{H}_{2}, \mathrm{CO}\right)$ are metered (see Figure 2) and introduced in separate quartz preheat channels. Figure 3 shows a cross-section of the reactor itself. The system provides four isolated preheat channels. Three of the channels are premixed just upstream of a $0.5 \mathrm{~mm}$ nozzle. The fourth stream flows around the outside, and it contains most of the flow $\left(\mathrm{O}_{2}\right.$ and the $\mathrm{N}_{2}$ not used for $\mathrm{Hg}$ and $\mathrm{H}_{2} \mathrm{O}$ transport). Water is metered as a liquid via a syringe drive, and is converted to vapor by an electric vaporizer before being mixed with the gases. Mercury vapor is generated by passing $\mathrm{N}_{2}$ through a bubbler/saturator that contains liquid $\mathrm{Hg}$ in a constant temperature bath. This vapor stream is then diluted.

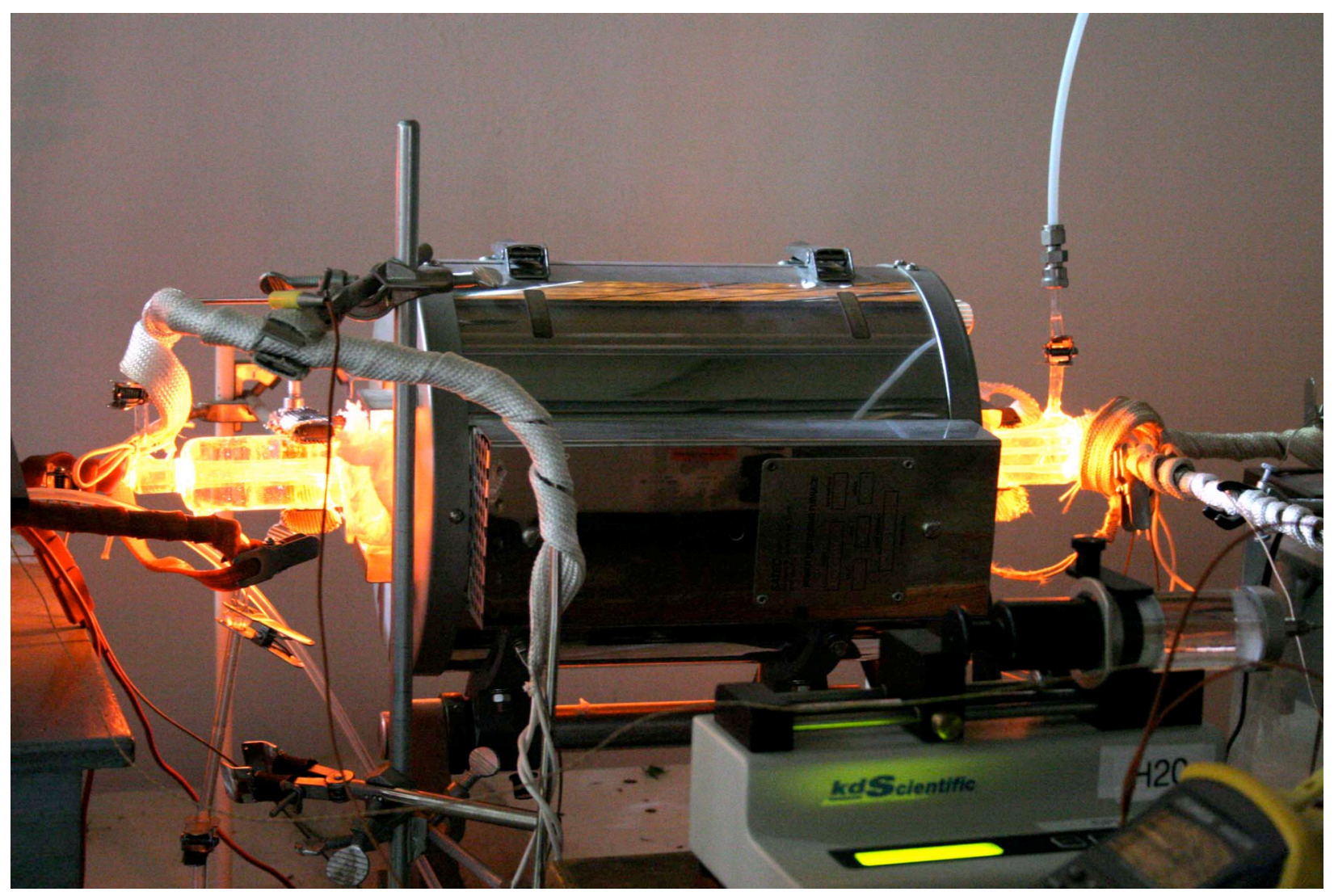

Figure 1. Quartz flow reactor system and clamshell oven. 


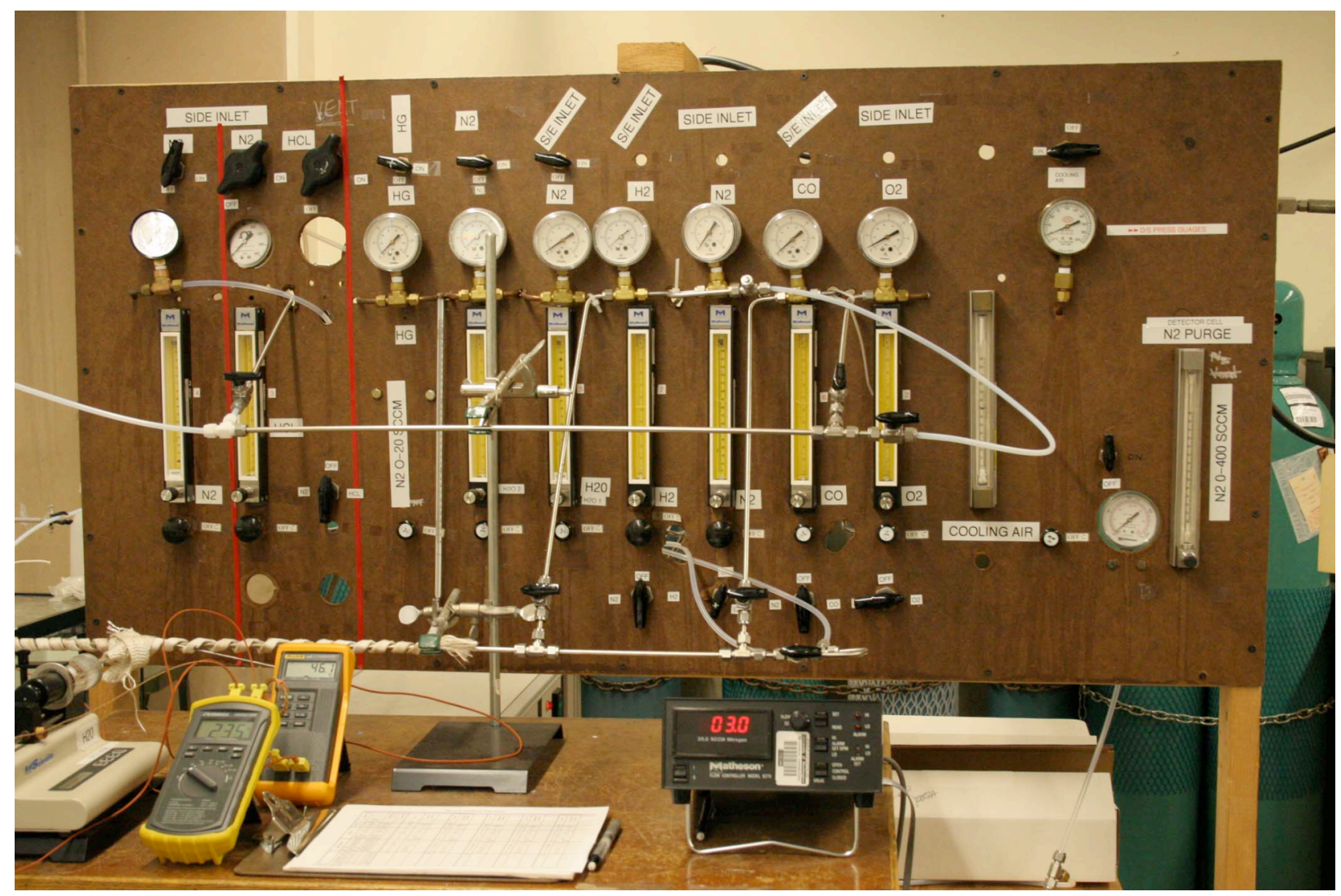

Figure 2. Manifold flow panel.

The details of the process are as follows. The reactor is designed to provide three distinct zones. The first allows for combining and preheating the premixed gas from the manifold system containing nitrogen, hydrogen, carbon monoxide and water. The reactor flow path turns the flow in two $180^{\circ}$ turns while exposing it to temperature, subsequently introducing it to zone 2 , a central mixing/reaction chamber. The second premixed line containing nitrogen, oxygen and hydrogen chloride is split at the entrance to the reactor, only to be recombined with the mercury stream within the preheat zone of the reactor at the entrance to zone 2 . This mix is then injected into the central mixing chamber through a $0.5 \mathrm{~mm}$ choked nozzle providing a turbulent mixing condition. At this point the mercury is combined with a mix of $\mathrm{HCl}$ and a combination of $\mathrm{H}_{2}$ and/or $\mathrm{CO}$, beginning the reaction zone. Previous calculations indicate that mixing occurs within the first $5.6 \mathrm{~cm}$ of zone 2, the length of which is $20.3 \mathrm{~cm}$. The last zone of the rector is the quench region. This portion of the reactor protrudes out the back of the clamshell furnace and is kept at $464 \mathrm{~K}$ with preheated gases manifolded in a way similar to that found in zone 1.

A modified Buck 400A mercury analyzer is used for continuous mercury monitoring of the flow stream. The Buck Analyzer measures only elemental mercury using ultraviolet optical absorption system and has a sensitivity of 0.01 micrograms of mercury. An absorption cell is suspended between an ultraviolet light source and a UV sensitive photo cell. Only light at $253.7 \mathrm{~nm}$ is absorbed by the mercury passing through the cell. The change in energy transmitted to the photo cell is detected, thus the amount of elemental mercury detected is directly related to the amount 


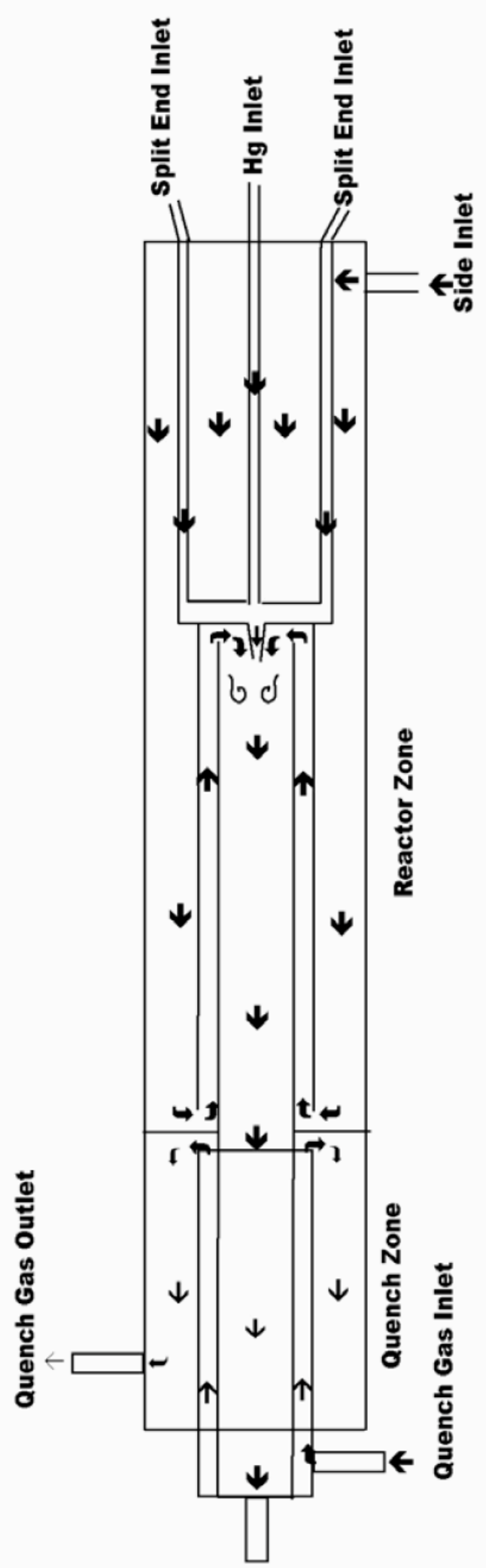

Figure 3. Schematic cross-section of the quartz flow reactor. 
of light at $253.7 \mathrm{~nm}$ which reaches the detector, or percent transmittance. The relationship between mercury concentration in the absorption cell and percent transmittance of the detector are related by Beer's law:

$$
\mathrm{I}=\mathrm{I}_{0} \mathrm{e}^{-\mathrm{kcl}}
$$

where: $\quad I=$ emergent beam intensity

$I_{0}=$ Incident beam intensity

$\mathrm{k}=$ constant of proportionality

$\mathrm{c}=$ Mercury concentration $\left(\mathrm{mole} / \mathrm{m}^{3}\right)$

$1=$ optical tube length

Modifications to the analyzer are extensive for this particular application. The detector is designed to operate on discreet samples drawn in with a pump at a flow rate of $1950 \mathrm{sccm}$, while in this test program, a continuous flow of $300 \mathrm{sccm}$ at atmospheric pressure must be monitored during each test series. The flow pump is bypassed to allow for these considerations. The detector cell is plumbed directly into the flow path immediately downstream of the reactor quench region. This helps minimize sequestration regions in the flow system. The absorption cell is heated to $400 \mathrm{~K}$ to eliminate water condensation from the flow stream onto the absorption cell surfaces, as this causes a known detector interference problem. Because of heating of the absorption cell, and subsequent heating of the Buck analyzer, additional exterior cooling in the form of a small fan blowing on the back of the instrument is added. In addition, the cavity in which the detector is positioned is vented to atmosphere. A shop air purge is retrofitted within the detector cell cavity to provide a constant amount of atmospheric water vapor variation of which is found to adversely affect the phototube detector. Even this small amount of water vapor is found to profoundly interfere with light transmittance at the operational frequency causing data to be unstable. A strip chart recorder is added to determine data trends.

Calibrations are conducted at the beginning and end of each test run. Analyzer calibration is conducted by introduction of a various known elemental mercury concentrations and developing a polynomial curve fit for the data. Baseline shift readily occurs in this instrument and are rectified by depriving the system of mercury and re-zeroing the Buck analyzer across the span of the instrument.

Cleaning of the mercury contaminated gasses is required before venting to atmosphere. Once the mercury laden stream is analyzed, the flow is ducted to an impinger containing a mixture of nitric acid and potassium permanganate, mixed per EPA method 29. Maintained in an ice bath, the impinger scrubs all elemental and oxidized mercury out of the gas stream before it was exhausted to atmosphere. Impinger liquid is appropriately disposed and replaced of at the end of each set of tests.

The data acquisition process in this experiment requires long reactor equilibration times and very delicate adjustments to the equipment. The presence of nitrogen is maintained in the flow circuit at all times. Time to reactor equilibration from a cold start to full operational capacity is five to seven days. Complete reactor purge is found to take approximately 48 hours. Data point equilibration times varied and are longest when hydrogen is involved, varying from ten minutes 
per data point for a calibration, to four hours for an acid calibration, to six hours when hydrogen is used. It is believed that the mechanism behind these phenomena involve both chemical and transport processes. Molecular sequestration occurred in a number of geometric spaces throughout the flow system, and is most likely also sequestered within the stainless steel of the supply manifolds. In addition, the internal flow structure of the reactor favored creation of recirculation zones. At very low concentrations, often on the order of $25 \mathrm{ppm}$, these recirculation zones also allowed for trapping of key molecules. These phenomena drove the very long equilibration periods experienced. Once these lag times are defined, the accuracy and repeatability of the experiment are assured.

Each test requires a procedural check list including verification of the flow streams for pressure and flow rate, maintaining flow conditioning water and ice baths and calibrating the equipment. The mercury bubbler provides vaporized mercury at a known concentration and is located just upstream of the reactor. The temperature of the water bath and the heated glass line are recorded. This stream is then introduced to a flow mix of nitrogen, oxygen and water vapor input at the farthest point upstream in the manifold, followed by hydrogen chloride and subsequently hydrogen and/or carbon monoxide. Each introduction is followed by the appropriate equilibration period for the reactor. Data are taken both by hand and by using a strip chart recorder for detector measurements. For each stream the line pressure and flow rates are documented. Temperatures of the water line, mercury bubbler and bubbler supply line, reactor, quench gas, and detector are documented as well as atmospheric temperature and pressure. Data sheets are generated on a custom basis for each test using an Excel spreadsheet and manufacturer supplied flow calibration curves for each flowmeter. A strip chart recorder is used to monitor the trend of the percent transmittance, and to ensure that instrument drift was monitored, detected and corrected.

This experimental configuration exhibit complex behaviors which limit the way test series are conducted. Equilibration times for adding species are found to an order of magnitude less than that found in subtracting species. Increasing temperatures require, again, less equilibration time than decreasing temperatures. And finally, it was found that when changing species mix it perturbed the system less to subtract nitrogen first and then to add additional or new gas species. Therefore all test series are conducted by increasing oxidizing species rather than decreasing them, and by subtracting neutral species before adding oxidizing species. Further, temperature surveys are conducted starting from $922 \mathrm{~K}$ increasing to $1200 \mathrm{~K}$. Violation of these rules caused unstable reactor operation and inconsistent data in all cases.

\section{Results and Discussion}

One of the first issues we addressed was the influence of water on mercury oxidation. Earlier quartz flow reactor work by Hall et al. $(1990,1991)$ had indicated significantly higher mercury oxidation values than later work here and elsewhere for similar residence times and reaction temperatures. Figure 4 compares data obtained from our earlier work and the literature with that of Hall. One difference was that the Hall experiments were conducted in dry gases, while the remaining work was done under water vapor concentrations typical of combustion products. Chemical kinetic modeling suggested that the presence of water suppresses the oxidation reaction via driving the $\mathrm{Cl}$ formation reaction into the reverse direction: 


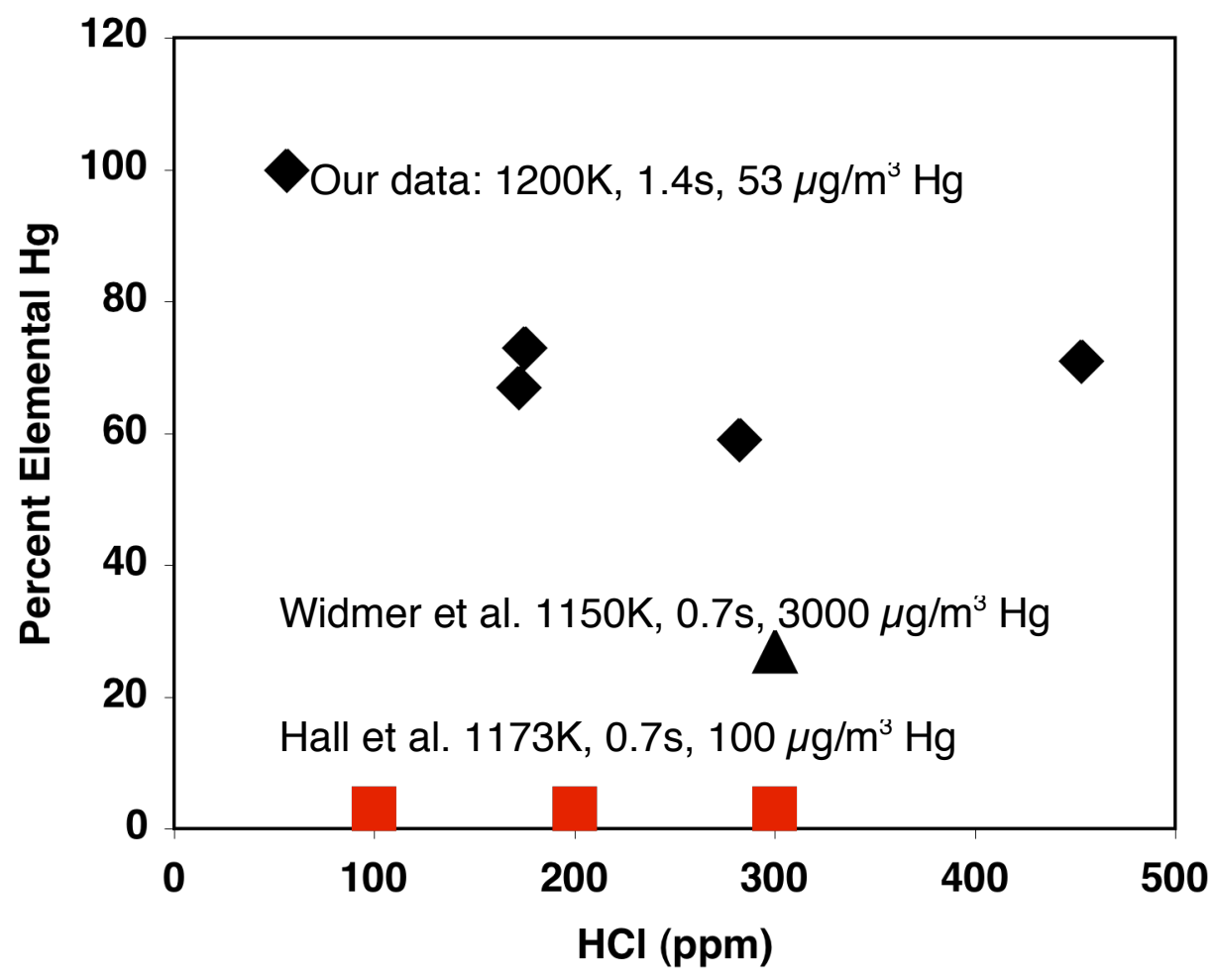

Figure 4. Comparison of oxidation extents for various experiments.

$$
\mathrm{HCl}+\mathrm{OH} \leftarrow \mathrm{Cl}+\mathrm{H}_{2} \mathrm{O}
$$

Experiments were performed in which the amount of water vapor was varied between zero and $14 \%$ (mole). For these experiments the initial $\mathrm{Hg}$ concentration was $846 \mu \mathrm{g} / \mathrm{m}^{3}$, the $\mathrm{O}_{2}$ concentration was $11 \%$ (mole), two levels of $\mathrm{HCl}$ were used (see Figure 5), and the balance was $\mathrm{N}_{2}$. The reactor temperature was $922 \mathrm{~K}$.

Figure 5 shows that oxidation is essentially complete in dry gases. Under the low $\mathrm{HCl}$ loading, increasing the water vapor concentration to typical combustion values did indeed significantly deactivate the oxidation process. With the higher $\mathrm{HCl}$ loading, the deactivation was much less pronounced. Although detailed chemical kinetic modeling of these specific experiments has not been done, the results suggest that the higher $\mathrm{HCl}$ concentrations are capable of forcing a more significant $\mathrm{Cl}$ concentration in the face of the reverse reaction driven by water vapor. Thus, it is clear that water has a significant role in the oxidation process, and it provides an explanation for the difference noted between the results of Hall et al. and others. 


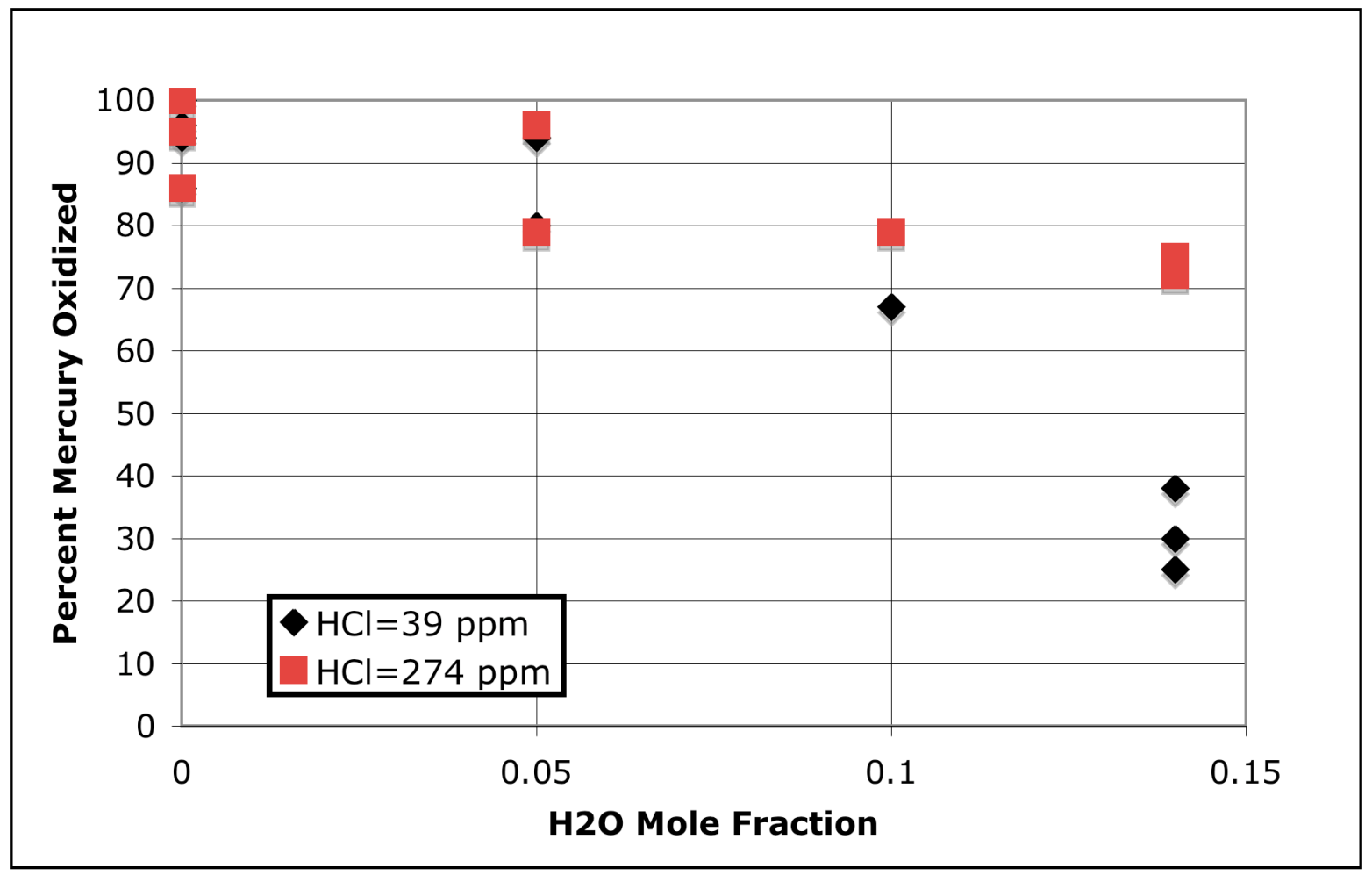

Figure 5. Influence of water vapor concentration on $\mathrm{Hg}$ oxidation.

Figure 6 shows baseline data on oxidation by $\mathrm{HCl}$ without any promoters. The conditions are identical to those of Figure 5 except the water concentration is $5 \mathrm{ppm}$. This shows many of the features that have been noted in earlier studies. First, there is no oxidation in the absence of $\mathrm{HCl}$. Next, the oxidation is strongly promoted by higher temperatures. In our present understanding of the process, this occurs due to higher concentrations of $\mathrm{Cl}$ being generated at higher temperatures, leading to more oxidation during quench. Finally, we see that much of the oxidation occurs with the first increments of $\mathrm{HCl}$ addition, and only a little more oxidation noted with increasing $\mathrm{HCl}$. 


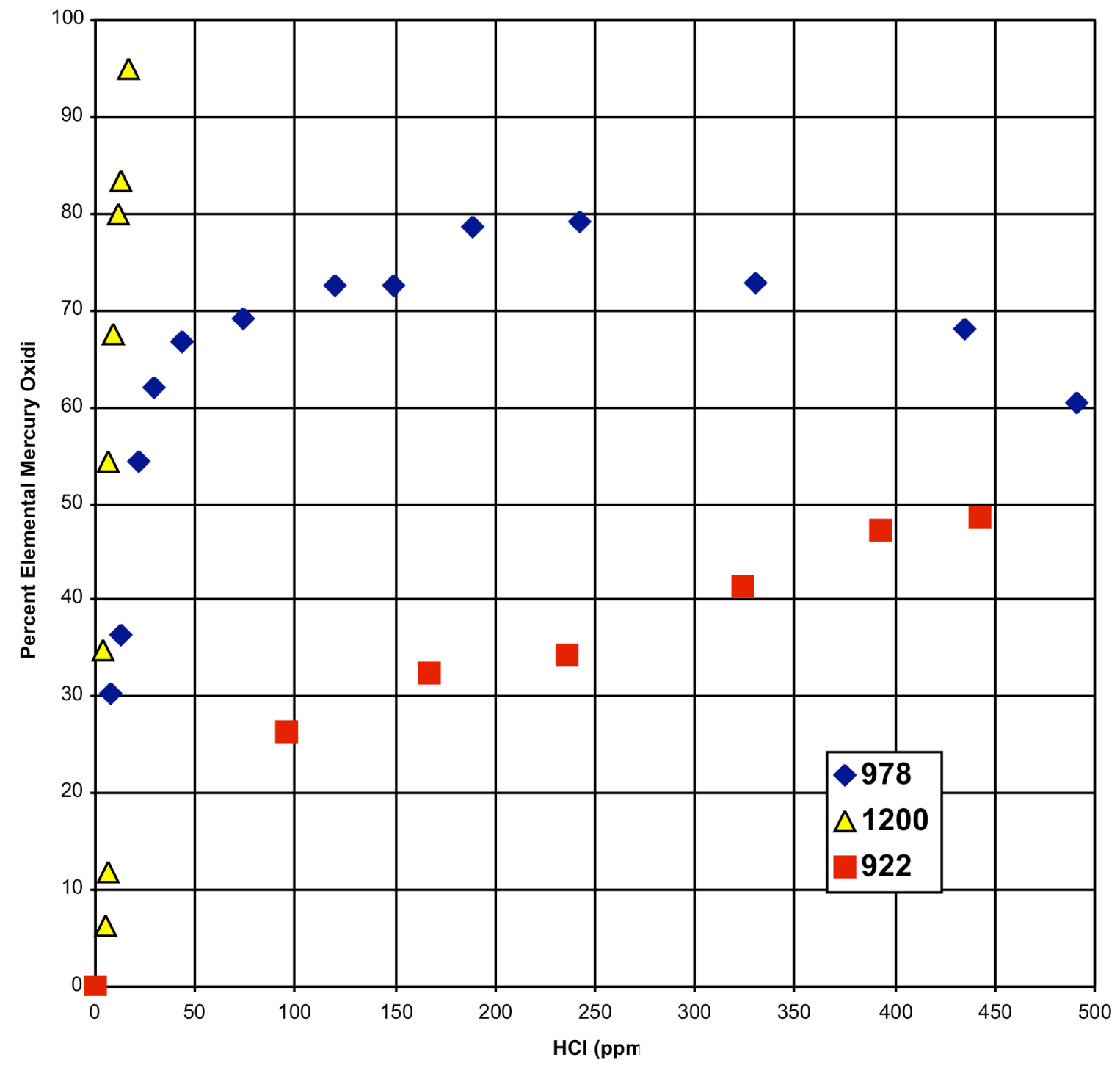

Figure 6. Oxidation of mercury by $\mathrm{HCl}$ in the absence of promoters at three temperatures (K).

\section{Conclusions}

At the end of the first year of the program, we have perfected the experimental system and achieved repeatable results. We repeated a series of baseline results and have shown that the oxidation as a function of temperature and $\mathrm{HCl}$ is consistent with past measurements. We also demonstrated the effect of water on the oxidation process. This solves one of the outstanding questions from the data record: why the results of Hall et al. $(1990,1991)$ give so much more fractional oxidation than those of others who have used similar experimental conditions. In the case of Hall, the dry experiments lead to much higher oxidation. 


\section{References}

Hall, B., O. Lindqvist, and E. Ljungström: Environmental Science and Technology 24, 108-111 (1990).

Hall, B., P. Schager, and O. Lindqvist: Water, Air and Soil Pollution 56, 3-14, (1991).

Livengood, C. D., M. H. Mendelsohn, and B. W. Lani: 95 ${ }^{\text {th }}$ Annual Conference of the Air and Waste Management Association, paper No. 451, Baltimore, MD (June 2002).

Niksa, S., and J. J. Helble: "Interpreting Laboratory Test Data on Homogeneous Mercury Oxidation I Coal-Derived Exhausts", EPA-DOE-EPRI Combined Power Plant Air Pollution Control Symposium, Chicago, IL (August 2001).

Qiu, J., R. O. Sterling, and J. J. Helble: "Development of an Improved Model for Determining the Effects of $\mathrm{SO}_{2}$ on Homogeneous Mercury Oxidation", 28th International Technical Conference on Coal Utilization \& Fuel Systems, Clearwater FL (March, 2003).

Sliger, R. N., J. C. Kramlich, and N. M. Marinov: Fuel Processing Technology 65, 423-438 (2000).

Widmer, N. C., J. A. Cole, W. R. Seeker, and J. A. Gaspar: Combustion Science and Technology 134, 315-326 (1998).

Xu, M., Y. Qiao, C. ZhengL. Li, and J. Liu: Combustion and Flame 132, 208-218 (2003). 